\title{
Social Relationships, Personality, and Anxiety During a Major Stressful Event
}

\author{
Niall Bolger \\ University of Denver
}

\author{
John Eckenrode \\ Cornell University
}

\begin{abstract}
Although it is commonly believed that social relationships buffer the effects of stress on mental health, these apparent buffering effects may be spurious reflections of personality or prior mental health. This possibility was investigated in a prospective study of a medical school entrance examination. Five weeks before the examination, $\mathrm{Ss}(N=56)$ rated their personality (extraversion and neuroticism) and social relationships (number of social contacts and perceived support). They then rated their anxiety for 35 days surrounding the examination. Controlling for personality and prior anxiety, social contacts buffered against increases in anxiety, whereas perceived support did not. Further analyses revealed that discretionary social contacts were beneficial whereas obligatory contacts were not.
\end{abstract}

It is now commonly believed that social relationships buffer the effects of stress on mental health. Although this belief is grounded in more than a decade of research (S. Cohen \& Syme, 1985; B. R. Sarason, Sarason, \& Pierce, 1990), some commentators have argued that the stress-buffering effects of social relationships may reflect personal rather than environmental resources (e.g., Gottlieb, 1983; Hansson, Jones, \& Carpenter, 1984; Heller, 1979; Thoits, 1982). Bolstering this claim is evidence that people's perceptions of social support are confounded with both their personality (Henderson, Byrne, \& Duncan-Jones, 1981 ) and their prior mental health (Monroe, Bromet, Connell, \& Steiner, 1986; Turner, 1981). Although contrary findings also exist (e.g., S. Cohen, Sherrod, \& Clark, 1986), the possibility that social support effects are spurious remains a serious threat to the validity of this area of research.

Two issues have hampered the resolution of this question; one is conceptual and the other is methodological. At the conceptual level, the literature has neglected structural and interactional features of relationships, such as network size and frequency of social contacts (Coyne \& Bolger, 1990; House \& Kahn, 1985). Thus, research showing the confounding effects of personality and prior mental health is based on perceived support measures of social relationships. We will argue that perceptions of support are more prone to these confounding effects than are structural and interactional measures.

At the methodological level, it is a major drawback that most existing social support research has used weak, cross-sectional, and retrospective designs (Monroe \& Steiner, 1986). Such designs are unsuitable for determining the causal role of social relationships in adaptation to stress. In this study, we sought to

We thank Jane Crawford for access to the sample and Paula Hanpeter for assistance with data collection. We also thank Daryl Bem, Sheldon Cohen, James Coyne, Geraldine Downey, Mark Foster, Harry Gollob, James House, Ronald Kessler, Richard Price, Debra Umberson, Amiram Vinokur, Elaine Wethington, Camille Wortman, and two anonymous reviewers for comments on previous drafts of this article.

Correspondence concerning this article should be addressed to Niall Bolger, who is now at the Department of Psychology, New York University, 6 Washington Place, Seventh Floor, New York, New York 10003. examine the stress-buffering effects of social relationships by performing a longitudinal, prospective study of a major stressful event.

The event we chose was a significant stressor among college students, a medical school entrance examination. Because examinations are scheduled events, we could obtain prior measures of both personal and social resources. We used a 5-week daily measurement design to monitor the independent effects of personality and social resources on mental health as the examination approached.

\section{Concepts of Social Relationships and Social Support}

Researchers have adopted two major approaches to measuring social relationships. The first approach operationalizes relationships in structural terms, that is, in terms of the number or frequency of social ties to family, neighbors, friends, and voluntary and religious organizations (e.g., Berkman \& Syme, 1979; Donald \& Ware, 1982). Measures stemming from this approach assess what is called social integration (Dunkel-Schetter \& Bennett, 1990; House \& Kahn, 1985). The second approach operationalizes relationships in functional terms, that is, in terms of the amount of instrumental and emotional support that the relationships provide (House \& Kahn, 1985; Tardy, 1985; Vaux, 1988). Functional measures usually focus on the perceived quality of one's relationships (e.g., how much love or caring others display) and assess what Gottlieb (1983) has called the "psychological sense of support."

The social support literature has focused primarily on support perceptions and has found that perceived support apparently buffers or reduces the negative effect of stress on mental health (S. Cohen \& Wills, 1985; Kessler \& McLeod, 1985; Wethington \& Kessler, 1986). This emphasis on perceived support reflects the reasonable assumption that people's support perceptions are more direct measures of the helpful features of relationships than are the cruder and more distal measures of social integration (S. Cohen \& Wills, 1985). Stress-buffering effects have been found less consistently for social integration (S. Cohen \& Wills, 1985; Kessler \& McLeod, 1985; Williams, Ware, \& Donald, 1981), although the paucity of studies of social 
integration effects makes it difficult to draw any firm conclusions (House \& Kahn, 1985).

This neglect of social integration has been criticized by some commentators. Coyne and DeLongis (1986), for example, label this trend "the 'cognitization' of the social support literature" (p. 457). They note an absence of studies of the concrete interpersonal transactions that presumably underlie social relationship effects. Similar concerns led House and Kahn (1985) to recommend that future studies include both structural and functional measures of social relationships, a recommendation we followed in this study.

\section{Threats to the Validity of Social Relationship Effects}

As we noted earlier, there is evidence that the apparent stressbuffering effect of social relationships is spurious. By spurious we mean that social relationships and mental health have a common cause that researchers have typically ignored. Such a common cause should meet three conditions: (a) It should be associated with social relationships, (b) it should itself be a stress buffer, that is, it should modify the effects of stressors on mental health (S. Cohen \& Edwards, 1989), and (c) when this common cause is statistically controlled, social relationships should no longer buffer the effects of stressors on mental health.

Because existing research has mostly used perceived support to index relationships, we will confine our discussion to this measure. The three conditions for rendering perceived support effects spurious are met by personality and prior mental health. Consider prior mental health, as least as it has been operationalized in various measures of psychological distress. It meets the first condition because prior psychological distress leads to subsequent decreases in perceived support (Turner, 1981). It meets the second condition because people who are initially high in distress are most emotionally reactive to stress (Coyne \& Downey, 1991; Hammen, Mayol, deMayo, \& Marks, 1986). Finally, it meets the third condition because researchers who have controlled for prior distress have not found a stress-buffering effect of support on distress (Monroe, 1983; Monroe et al., 1986).

Among personality traits that may generate an apparent stress-buffering relationship between perceived support and mental health, neuroticism meets the conditions described earlier. It relates negatively to perceived support (Procidano \& Heller, 1983; Sarason \& Sarason, 1985). It interacts with stress to predict mental health: The state-trait theory of anxiety predicts that individuals high in neuroticism are most emotionally vulnerable to stress (Endler \& Edwards, 1982; Eysenck \& Eysenck, 1985; Spielberger, Gorsuch, \& Lushene, 1970; see Bolger, 1990; Bolger \& Schilling, in press; Ormel, Stewart, \& Sanderman, 1989, for recent confirmations of this theory). Finally, when neuroticism is statistically controlled, the stress-buffering effect of support on mental health disappears (Henderson et al., 1981).

In sum, existing evidence suggests that the stress-buffering effect of perceived support may be spurious. Whether this problem also applies to social integration is unclear, given the paucity of research using this measure. There is, however, reason for thinking that social integration is less prone than per- ceived support to a particular form of spuriousness, that is, spuriousness due to mood-driven response biases.

It is well established that positive and negative moods bias social judgments: Positive moods induce positivity bias and negative moods induce negativity bias (Clark \& Williamson, 1989). Personality and prior mental health may spuriously create buffering effects through these mood-induced response biases. Clearly, prior mental health, whether reflected in measures of anxiety, depression, or hostility, affects mood. Also, major personality dimensions such as extraversion and neuroticism can be regarded as trait forms of positive and negative moods, respectively (Costa \& McCrae, 1980; Watson \& Tellegen, 1985). Thus, personality and prior mental health may lead to moodinduced bias in people's reports of their social relationships. For example, people high in neuroticism may report that they are less supported than they actually are. If personality and prior mental health also have a stress-buffering effect on current mental health, then studies that ignore these factors will find a spurious stress-buffering effect of social relationships.

One would not expect such mood-driven biases to operate on judgments about issues that have little or no emotional content. Thus, judgments about concrete, factual issues such as the frequency of one's social contacts should be less prone to bias than judgments about emotionally toned issues such as whether one is loved or cared for. Therefore, a key hypothesis of this study was that measures of social integration are less vulnerable to response-bias effects than are measures of perceived support.

Consistent with this hypothesis, L. H. Cohen, Towbes, and Flocco (1988) found that experimentally induced depressed moods lower general perceptions of support. Similarly, Procidano and Heller (1983) found that negative mood lowered people's perceptions of support from friends. In contrast, L. H. Cohen et al. (1988) found no effects of depressed mood on reports of specific supportive acts in the previous month. This suggests that concrete, factual measures such as social integration are less likely to be affected by negative moods than are more global and subjective measures such as perceived support.

\section{Social Relationships and Adaptation to a Medical School Entrance Examination}

To examine the stress-buffering effects of social relationships, we designed a study of a major stressful event among premedical students, the Medical College Admissions Test (MCAT). The MCAT is a day-long standardized test taken by almost all applicants to medical school. Because it is a major hurdle in the medical school entry process and can have important career consequences, the MCAT is highly stressful.

Major examinations such as the MCAT are useful for studying the stress-buffering effects of social relationships for several reasons. First, stress-buffering effects can be more easily detected in intensive, prospective studies of a major stressor than in conventional retrospective studies. Buffering effects are diffcult to detect in retrospective studies using life-event inventories: Such studies typically sample few respondents who have experienced a recent major stressor (House, Umberson, \& Landis, 1988). In contrast, intensive studies of a major stressor can examine stress buffering when the event can be expected to have its largest impact-near the time it occurs. 
Second, because examinations entail the same objective event for all people, investigating such events ensures that differences in stress outcomes are not due to unmeasured differences in the types of stressful events people experience. Many naturally occurring types of stressors are heterogeneous. For example, not all motor accidents are equally severe, and this heterogeneity may explain why some persons become more distressed than others.

Third, examinations do not inherently involve changes in social relationships. Many stress-buffering studies have confounded measures of stress and support because they have included life events that involve major changes in relationships, such as divorce and widowhood (Thoits, 1982).

Finally, studying an examination allowed us to test the buffering hypothesis within persons over time. In conventional, between-subjects studies, researchers evaluate stress-buffering efficacy by comparing people who have experienced high stress with those who have not. By contrast, we could monitor the same people as they moved from a time of low stress to a time of high stress, and we could determine whether prior social relationships differentiated those who became highly distressed from those who did not. Because each person serves as his or her own control, this design is more powerful than the conventional between-persons strategy.

In this study, we prospectively measured two major personality dispositions, extraversion and neuroticism. Both have previously been shown to relate to social relationship measures (I. G. Sarason \& Sarason, 1985), and, as noted earlier, at least one study suggests that the stress-buffering effect of social relationships may be a spurious product of neuroticism (Henderson et al., 1981).

While controlling for these personality traits and for prior mental health, we wished to test whether the stress-protective effect of social relationships would emerge as the examination approached, that is, as stress increased. To trace this effect, we obtained daily measures of anxiety from 17 days before to 17 days after the examination. We also included both structural (i.e., social integration) and functional (i.e., perceived social support) measures of social relationships. This allowed us to test a key hypothesis - that social integration would be a more effective stress buffer than perceived support once personality and prior mental health were controlled. Furthermore, we wished to see which facets of social integration (e.g., kin, neighbors, and work) and perceived support (e.g., instrumental and emotional) were most efficacious as stress buffers.

\section{Method}

\section{Design and Sample}

We recruited subjects at an MCAT registration session at a major university, at which 226 students registered. Recruitment took place 9 weeks before the examination. As students left the registration hall, they received a handout inviting them to take part in a study of examination stress. For their participation, we offered subjects $\$ 20$ and feedback on the results of the study. Because the flow of students through the hall was very swift, only 106 students received handouts. Of these, 84 said they were interested in learning more about the study.

Four weeks later ( 5 weeks before the examination), we mailed interested persons $\$ 5$ in cash and an initial (Time 1) questionnaire that assessed demographic, personality, and social relationship variables. Sixty-eight persons agreed to participate in the study and completed the Time 1 questionnaire.

Seventeen days before the examination, subjects received the first of five booklets of daily diaries (self-report questionnaires) and a further $\$ 5$ in payment. Each booklet contained seven daily diaries. The diaries measured changes in anxiety during the 5 weeks surrounding the examination. Subjects completed their diaries daily at bedtime, and this task usually took less than 2 min. Subjects received additional booklets each week and returned the booklets by mail weekly. On completion of the diary phase of the study, each subject received a final $\$ 10$ payment. Fifty-six subjects completed the Time 1 questionnaire and all diaries up to and including the examination day-the 18 th day of the diary period.

This final sample $(N=56)$ consisted of 28 men and 28 women; the average age was 20.3 years $(S D=0.8)$, the average GPA was $3.4(S D=$ $0.3)$, and the average MCAT score was $63.7(S D=7.6)$. We were concerned that this sample might not be representative of the population that took the examination. Of the 160 students who took the examination-recall that 226 had registered to take it-only $35 \%(56 / 160)$ provided complete data in this study, that is, data up to and including the examination day. We obtained the GPA and MCAT scores of students who took the test and compared these scores with those of our sample. The GPA and MCAT means for our sample closely matched those of the population (population GPA: $M=3.37, S D=0.38, z=0.56, n s$ for a test of the hypothesis that the sample $[M=3.40]$ was randomly drawn from a population with $M=3.37$; population MCAT score: $M=62.1$, $S D=8.3, z=1.06, n s$, for a test of the hypothesis that the sample $[M=$ 63.7] was randomly drawn from a population with $M=62.1$ ).

\section{Independent Variables}

Social integration. Social integration was assessed in the Time 1 questionnaire by using the Social Network List (S. Cohen, 1991). Like other social integration measures (e.g., Berkman \& Syme, 1979; Williams, Ware, \& Donald, 1981), the Social Network List obtains data on various domains of social integration such as kin, friends, and neighbors. For each domain, subjects reported the number of persons they interacted with at least once during a typical 2-week period. The contact could be in person or by telephone. The use of a typical 2-week period ensures that social integration is measured at a level of temporal generality similar to that for typical perceived support measures. We obtained reports for each of eight social integration domains: (a) parents, (b) other relatives, (c) members of religious groups, (d) members of leisure groups, (e) co-workers (if the subject had a part-time job), (f) classmates, (g) friends, and (h) neighbors. We constructed an additive index that was based on responses to these eight items (index $M=24.9$ persons, $S D=7.3$ persons).

Note that the same individual could be nominated in several social integration domains, for example, one could interact with the same person in a leisure group and in a religious group. This overlap will increase the correlation between the social integration subscales. In evaluating the impact of any particular subscale, therefore, we adjusted for its correlation with the other subscales (see Results section).

Perceived social support. We used the Social Provisions Scale (Cutrona \& Russell, 1987; Russell \& Cutrona, 1984), included in the initial questionnaire, to measure perceived support. This 24 -item instrument operationalizes Weiss's (1974) six social support functions: attachment, social integration, reassurance of worth, reliable alliance, guidance, and opportunity for nurturance. Typical items include "there are people I can depend on to help me if I really need it," "there is no one I feel comfortable talking about problems with," and "I feel a strong emotional bond with at least one other person." Subjects rated the 24 items on a scale from strongly disagree (1) to strongly agree (4). We computed 
the total perceived support score by summing scores on all 24 items $(M=82.2, S D=8.2)$. The reliability of the total scale (Cronbach's alpha) was .87 .

\section{Dependent Variable: Anxiety}

The daily diary instrument contained three items from the Profile of Mood States (Lorr \& McNair, 1971): (a) "on edge," (b) "uneasy," and (c) "nervous." These were the three highest loading items on an anxiety factor obtained in a validation study using college students (see Lorr \& McNair, 1971, p. 26). Respondents rated each item on the extent to which they had experienced the particular emotion during the previous $24 \mathrm{hr}$. They used the following 5-point scale: $1=$ not at all, $2=a$ little, $3=$ moderately, $4=$ quite a bit, $5=$ extremely. We computed scale scores by summing the item scores. The scale ranged from 3 to 15 units. The reliability of the scale (Cronbach's alpha), based on all the diary observations, was .87 .

For analytic purposes, we averaged each person's daily anxiety scores for diary Days 1-10 and 11-17. We chose this division of days to distinguish a time that we thought would be psychologically meaningful to the MCAT students-the final week before the examination (Days 11-17). We reasoned that this final week would be a time when the imminence of the exam could not be ignored and when feelings of anxiety would grow. Thus we intended the Day 1-10 measure of anxiety to serve as a baseline or control period against which to gauge later increases in anxiety.

\section{Control Variables}

Initial anxiety. See the section on the dependent variable above.

Personality. In the initial questionnaire, each subject completed Form B of the Eysenck Personality Inventory (EPI; Eysenck \& Eysenck, 1964). We measured extraversion using responses to 24 items in the EPI. Each item used a yes-or-no format; each yes was scored 1 and each no was scored 0 ; thus, the total score could range from 0 to 24 . The sample mean score was $13.7(S D=3.8)$. Typical items include "do other people think of you as lively?" and "generally, do you prefer reading to meeting people?" As with extraversion, we measured neuroticism using 24 items from the EPI, and the total score could range from 0 to 24 . The sample mean score was $12.1(S D=4.7)$. Typical items include "would you call yourself a nervous person?" and "are you troubled with feelings of inferiority?"

Table 1

Interrelationships of Social Integration, Perceived Support, Personality, and Daily Anxiety: Pearson ProductMoment Correlations $(N=56)$

\begin{tabular}{lcc}
\hline \multicolumn{1}{c}{ Variable } & $\begin{array}{c}\text { Social } \\
\text { integration }\end{array}$ & $\begin{array}{c}\text { Perceived } \\
\text { support }\end{array}$ \\
\hline Social integration & - & $.31^{*}$ \\
Perceived support & $.31^{*}$ & $-6^{*}$ \\
Extraversion & $.34^{*}$ & $-.31^{*}$ \\
Neuroticism & -.11 & -.14 \\
Initial anxiety & & \\
$\quad(M$ over Days 1-10) & -.19 & $-.28^{*}$ \\
\hline $\begin{array}{l}\text { Prexamination anxiety } \\
(M \text { over Days 11-17) }\end{array}$ & $-.39^{*}$ & \\
\hline
\end{tabular}

$* p<.05$, two-tailed.
Table 2

Standardized Regression Coefficients Relating Social Integration and Perceived Support to Preexamination Anxiety, Controlling for Initial Anxiety, Extraversion, and Neuroticism $(N=56)$

\begin{tabular}{lcc}
\hline $\begin{array}{c}\text { Relationship to } \\
\text { preexamination anxiety }\end{array}$ & $\begin{array}{c}\text { Social } \\
\text { integration }\end{array}$ & $\begin{array}{c}\text { Perceived } \\
\text { support }\end{array}$ \\
\hline $\begin{array}{l}\text { Unadjusted (Pearson product- } \\
\text { moment correlation) }\end{array}$ & $-.39^{*}$ & $-.28^{*}$ \\
$\begin{array}{l}\text { Controlling for } \\
\text { Neuroticism alone }\end{array}$ & $-.34^{*}$ & -.16 \\
$\quad$ Extraversion alone & $-.26^{*}$ & -.17 \\
$\quad$ Neuroticsm + extraversion & $-.27^{*}$ & -.11 \\
$\quad$ Neuroticism + extraversion, + & $-.20^{*}$ & -.14 \\
$\quad$ initial anxiety & & \\
\hline
\end{tabular}

$* p<.05$, two-tailed.

\section{Results}

\section{Interrelationships of Social Integration and Perceived Support}

Table 1 presents Pearson product-moment correlations showing how the social relationship measures related to one another and to personality and anxiety. Several findings are noteworthy. First, social integration and perceived support correlate positively, but only to a moderate extent, $r(54)=.31, p<$ .05 , two-tailed (all later tests we report are two-tailed). Second, social integration and perceived support differ in their relationships to personality. Although social integration and perceived support both correlate positively and significantly with extraversion, only perceived support relates significantly to neuroticism. Subjects high in neuroticism tend to perceive that they have inadequate social support, whereas subjects low in neuroticism tend to perceive that they have adequate social support, $r(54)=-.31, p<.05$.

Finally, the negative correlation between daily anxiety and both social integration and perceived support is greatest during the high-stress period. This is consistent with the hypothesis that social relationships buffer the effects of stress. Although neither social integration nor perceived support relate significantly to initial anxiety, both show moderate correlations with anxiety in the final week before the examination.

\section{Social Relationships and Increases in Daily Anxiety Under Stress}

We have seen that both measures of social relationships correlate with personality and with preexamination anxiety. Do both measures predict preexamination anxiety equally well when we statistically control for personality and initial anxiety? The regression results presented in Table 2 show that the relationship of perceived support to preexamination anxiety is mostly confounded with personality, whereas this is less true for the relationship of social integration to anxiety.

Turning first to perceived support, we can see that its significant relationship to preexamination anxiety, $r(54)=-.28, p<$ .05 , falls sharply when we introduce controls for extraversion 
(reduced to $\beta=-.17, n s$ ) or neuroticism (reduced to $\beta=-.16$, $n s)$. Simultaneously controlling both personality measures reduces the original coefficient to roughly one third its original value $(\beta=-.11, n s)$. The inclusion of initial anxiety as a control has little additional effect.

In contrast, the significant relationship between social integration and preexamination anxiety, $r(54)=-.39, p<.05$, is largely unaffected when we control for neuroticism (it is reduced to $\beta=-.34$; recall that social integration is only weakly related to neuroticism). Controlling for extraversion-to which it was moderately related-does reduce the social integration effect (to $\beta=-.26, p<.05$ ), although it remains statistically significant. This relationship declines further, but remains significant, when we control for prior anxiety $(\beta=-.20, p<.05)$. These results show that the effect of social integration on anxiety is relatively immune to rival hypotheses based on personality and prior anxiety, whereas the effect of perceived support on anxiety is not. ${ }^{\mathrm{I}}$

We can see these stress-buffering effects of social integration in a more graphic way by examining changes in the relationship between social integration and anxiety on a day-to-day basis. We illustrate this by using anxiety scores obtained during 28 days of the diary period-from 17 days before the examination to 10 days after the examination. Fifty-four persons provided complete data over this 28-day period. (We used only 28 of the 35 diary days to maximize the $N$ in the analysis).

Figure 1 shows mean levels of anxiety, adjusted for extraversion and neuroticism, over this 28-day period for groups with low and high social integration. We defined low and high social integration as the top and bottom $20 \%$, respectively, of the social integration distribution ( $n=11$ in each case). Given an underlying linear social integration effect, the apparent size of this effect can be made larger or smaller, depending on where one divides the distribution. We chose to compare the top and bottom $20 \%$ of the social integration because we reasoned that this split would be extreme enough to show the buffering effect clearly, without being so extreme as to be of no practical significance.

There is, on average, a small negative relationship between social integration and anxiety over the first 10 days of the diary period. This is consistent with the data presented earlier. Recall

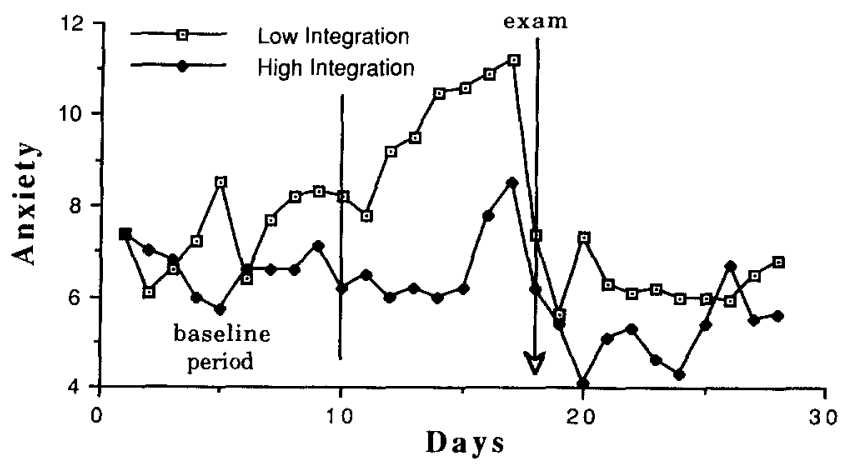

Figure 1. Daily anxiety during 28 days surrounding the examination, by level of social integration, controlling for extraversion and neuroticism. that when we averaged people's anxiety scores over these 10 days and correlated them with social integration, we obtained a nonsignificant correlation of -.20 . Unlike the data presented in Table 1, however, the mean differences displayed in Figure 1 reflect the partial correlation between social integration and anxiety when extraversion and neuroticism are controlled.

The relationship between social integration and anxiety becomes particularly large during the week immediately before the examination, and it declines sharply after the examination. This pattern corresponds to a buffering model: The benefits of social integration are most evident in a time of high stress.

\section{What Aspects of Social Integration Buffer the Effects of Examination Stress?}

Knowing that social integration buffers the effects of examination stress does not allow us to determine which aspects of social integration are most helpful. We conducted further analyses in which we distinguished four specific sources of people's social integration: (a) kin (family and relatives), (b) members of voluntary organizations (clubs and college societies) and religious groups, (c) co-workers and classmates, and (d) friends and neighbors. These distinctions are commonly used in research on social integration effects (e.g., Berkman \& Syme, 1979; House, Robbins, \& Metzner, 1982; Thoits, 1983).

Table 3 shows how these components of social integration correlate with one another and with personality and anxiety. There are at least three noteworthy patterns in the table. First, the components do not correlate strongly with one another. Although most of the correlations are positive, integration with co-workers or classmates correlates negatively with integration with kin, $r(54)=-.16, n s$, and with members of leisure and religious groups, $r(54)=-.06$, $n s$.

The second noteworthy pattern is that not all social integration components show similar correlations with personality. Only kin integration shows a substantial relationship with neuroticism, $r(54)=.25, p<.05$ : As neuroticism increases, so do levels of integration with kin. Extraversion correlates with only two of the four components. It correlates weakly with integration with members of leisure and religious groups, $r(54)=.22$, $p<.1$, but it correlates more strongly with integration with friends and neighbors, $r(54)=.34, p<.05$. Finally, only these latter two variables predict preexamination anxiety.

Like Table 2, Table 4 presents a decomposition of the effects of the four social integration components on preexamination

\footnotetext{
${ }^{1}$ Recall that these results are based on a division of daily anxiety into Days 1-10 and 11-17 (Day 18 was the examination day). In making this division, we assumed that only in the final week before the exam would students' anxiety show large increases. In response to a reviewer's query, we reran our analyses using 10 alternative divisions of days, 5 earlier and 5 later than the current division (at Day 11). Our results were unchanged for 7 of the 10 divisions. When we made divisions close to the examination day, however, at Days 14, 15, and 16, the social integration effect waned. This is because its buffering effect had already emerged by that time (see Figure 1). By including this effect in our control measure of anxiety, we found no additional social integration effect.
} 
Table 3

Interrelationships of Social Integration Components, Personality, and Daily Anxiety:

Pearson Product-Moment Correlations $(N=56)$

\begin{tabular}{lcccc}
\hline & \multicolumn{5}{c}{ Types of social integration } \\
\cline { 2 - 5 } & Kin & Leisure-religious & Work-school & Friends-neighbors \\
\hline$M$ & 2.9 & 4.6 & 9.5 & 7.9 \\
$S D$ & 1.3 & 4.4 & 2.7 & 4.3 \\
Kin & - & - & & \\
Leisure-religious & $.24^{*}$ & -.06 & -10 & \\
Work-school & -.16 & .16 & .12 & $-34^{* *}$ \\
Friends-neighbors & .15 & -.10 & .10 & -.16 \\
Extraversion & .08 & -.14 & -.03 & -.14 \\
Neuroticism & $.25^{* *}$ & $-.27^{* *}$ & -.10 & $-.31^{* *}$ \\
Initial anxiety & -.01 & & & \\
Preexamination anxiety & .06 & & & \\
\hline
\end{tabular}

${ }^{*} p<.10$, two-tailed. ${ }^{* *} p<.05$, two-tailed.

anxiety. On the first row of Table 4, we present partial relationships (standardized betas) between each of the four social integration measures and preexamination anxiety. Holding the other social integration measures constant, integration with kin correlates positively with preexamination anxiety, although the effect is nonsignificant, $\beta(50)=.16$, ns. Integration with members of leisure and religious groups correlates negatively with anxiety, $\beta(50)=-.26, p<.05$, as does integration with friends and neighbors, $\beta(50)=-.28, p<.05$.

Controlling for personality and initial anxiety leaves this pattern of results largely unchanged, although the magnitudes of the coefficients decline. Although we showed earlier that social integration buffered the effect of stress, this analysis reveals that integration with classmates and with co-workers (among those with part-time jobs) does not, $\beta(47)=-.04, n s$. Moreover, integration with kin predicts later increases in anxiety under stress, $\beta(47)=.16, p<.1$. Only integration with members of leisure and religious groups, $\beta(47)=-.15, p<.1$, and integration with friends and neighbors, $\beta(47)=-.15, p<.1$, show a stress-buffering effect similar to that found earlier for the overall measure of integration.

\section{Discussion}

This study has two main findings. First, when we statistically controlled extraversion, neuroticism, and prior anxiety, social integration protected against increases in anxiety under stress, whereas perceived social support did not. Second, not all forms of social integration were beneficial. Although more discretionary forms of social integration-contacts with friends and neighbors and with leisure and religious groups-buffered stress, integration at work and at school did not. Moreover, kin integration exacerbated the negative effects of stress.

\section{Conceptual Status of Perceived Support}

We hypothesized that one mechanism through which personality and prior distress could generate spurious buffering effects was through mood-induced response biases. We further hypothesized that, unlike social integration, perceived support would be particularly prone to this mood-mediated spuriousness. The pattern of results confirmed our predictions. The effects of both social integration and perceived support were

Table 4

Standardized Regression Coefficients Relating Social Integration Components to Preexamination Anxiety, Controlling for Initial Anxiety, Extraversion, and Neuroticism $(N=56)$

\begin{tabular}{lllll}
\hline & \multicolumn{4}{c}{ Types of social integration } \\
\cline { 2 - 5 } $\begin{array}{c}\text { Relationship to } \\
\text { preexamination anxiety }\end{array}$ & Kin & Leisure-religious & Work-school & Friends-neighbors \\
\hline $\begin{array}{l}\text { Unadjusted partial } \\
\quad \text { relationship }\end{array}$ & .16 & $-.26^{* *}$ & -.06 & $-.28^{* *}$ \\
$\begin{array}{l}\text { Controlling for } \\
\text { Neuroticism alone }\end{array}$ & .03 & -.21 & -.13 & -.20 \\
$\quad \begin{array}{l}\text { Extraversion alone } \\
\text { Neuroticism + extraversion }\end{array}$ & .16 & -.20 & -.07 & -.16 \\
$\quad \begin{array}{l}\text { Neuroticism + extraversion }+ \\
\text { initial anxiety }\end{array}$ & $.16^{*}$ & -.17 & -.12 & -.14 \\
\hline
\end{tabular}

${ }^{*} p<.10$, two-tailed. ${ }^{* *} p<.05$, two-tailed. 
reduced when personality and prior distress were controlled, but the perceived support effect was most strongly affected and became nonsignificant.

Although perceptions of support have been conceptualized as an independent attribute of personality (e.g., B. R. Sarason, Pierce, \& Sarason, 1990; I. G. Sarason, Sarason, \& Shearin, 1986), the results of this study do not support this view. If perceived support functions as an attribute of personality independent of extraversion and neuroticism, then one would expect it to have a stress-buffering effect even when these traits are controlled. Furthermore, perceived support does not appear to be a mediator or conduit of the effects of extraversion or neuroticism. For this to be so, perceived support should be correlated with extraversion and neuroticism, and it should affect mental health independently of them (J. Cohen \& Cohen, 1983). Whereas perceived support is correlated with these traits, for the case of examination anxiety at least, it does not affect mental health independently of them.

\section{Social Integration as a Stress Buffer}

It is important to consider why we found a buffering effect of social integration in the current study, whereas previous researchers have tended not to find such effects. Could it be that our finding arose by chance? Although this is a possibility, we believe the discrepancy is attributable to our prospective design and our focus on a single major stressful event. Previous studies of stress buffering have usually relied on life-event counts rather than on studying a single life event in depth. For example, neither of two major reviews of the literature included any study that examined the buffering effect of social integration on the relationship between a single major life event and mental health (S. Cohen \& Wills, 1985; Kessler \& McLeod, 1985).

As noted earlier, there is reason to expect that buffering effects will be more easily obtained in prospective studies of single major life events than in retrospective studies using life event checklists. In studies of life crises, it is easier for investigators to obtain measures of mental health close to the occurrence of the event, when mental health effects are likely to be most pronounced. In retrospective studies using life event inventories, few people will be sampled who have experienced a major life event recently, that is, within the previous few weeks. Therefore, the chances of detecting strong stress effects, and by implication, strong stress-buffering effects will be lessened (House, Umberson, \& Landis, 1988).

Given this argument, then, it is significant that another recent in-depth study of a major life event also found a buffering effect of social integration. In a community study of the physical and mental health consequences of unemployment, social integration had a strong stress-buffering effect, whereas perceived social support had only minor effects on health (House, Williams, \& Kessler, 1989). Although further research using major stressors is needed to settle this issue, we feel that the results to date confirm the importance of attending to structural features of relationships as stress buffers.

\section{Components of Social Integration}

We found that not all types of social integration were equally useful for relieving distress. In particular, only discretionary contacts-ties to religious and leisure groups and ties to friends and neighbors-were effective. Less discretionary contacts, those in school and work, did not protect against the effects of stress. In some respects, these results resemble those found by House et al. (1989): They found that informal social contacts were the most important buffers of stress among unmarried persons (the marital tie was the basis of social integration among the married). Discretionary contacts were also found to be particularly important in a recent study of the effects of social integration on mortality conducted by Moen, DempsterMcClain, and Williams (1989). Married women in upstate New York in the 1950s who participated in voluntary organizations showed lower mortality levels 30 years later, compared with women who were nonparticipants. Although there are substantial differences between the present study and those of Moen et al. and House et al., taken together, the studies suggest that discretionary social ties are more important than nondiscretionary ties-marriage excepted-in buffering stress.

In contrast to more discretionary types of social integration, integration with kin exacerbated the effects of stress. We think this effect may be due to the specific population and specific stressor: Anecdotal evidence suggests that MCAT students felt considerable parental pressure to perform well on this test. Those students with greater contact with their parents are more likely to have felt such pressure and the distress associated with it.

\section{Mechanisms Underlying the Social Integration Effect}

How does that salutary effect of social integration operate? It is clear from our results that the mechanism cannot involve global perceptions of support, because perceived support has no stress-buffering effect independent of social integration. This suggests that the mechanisms by which social relationships protect against the effects of stress may be more subtle than previously thought. There may be at least two processes at work. The first of these involves interactions that an observer would label as supportive but that one or all of the participants may not. The second process involves interactions that are not ostensibly supportive, that is, interactions that are not oriented toward alleviating stress, but that may nonetheless have stressreducing effects.

Consider the first of these processes. Although supportive interactions are usually thought to involve people's conscious awareness of an event as stressful and their conscious mobilization of support in response to it, many supportive interactions may not proceed in this fashion. For example, people may not explicitly seek the support they receive, nor may they label the support they receive as support (Coyne \& Bolger, 1990; Eckenrode \& Wethington, 1990; Lieberman, 1986).

In this study, we found evidence that people may not explicitly seek support when we attempted to explain the social integration effect in terms of subjects' reports of their coping efforts. before the examination. We measured six types of coping efforts (i.e., problem-focused, seeking support, focusing on the positive, distancing, wishful thinking, and self-blame; see Folkman \& Lazarus, 1985) at 5 weeks before and again at 10 days before the examination, and we summed people's coping scores across the two time points. We reasoned that if the social inte- 
gration effect was mediated by the types of coping strategies subjects used-particularly, seeking support-then this effect would be substantially reduced when we statistically controlled for coping (J. Cohen \& Cohen, 1983). The effect, however, was unchanged when we controlled for coping. Thus, people's reports of their conscious efforts to cope with the upcoming examination did not mediate the social integration effect.

There is also evidence that people may not always interpret the support they receive as support. In other words, the process of obtaining support from one's social network may proceed so smoothly for most people that they are unable to report accurately on it (Lieberman, 1986). Consistent with this possibility, in a study of married couples, Bolger, Kessler, and Schilling (1991) found that the supportive acts by a spouse that were not noticed or not defined as support by the recipient were the most effective buffers of daily stress. Acts recognized as supportive were ineffective in buffering stress.

The second process that may underlie the social integration effect involves interactions that are not ostensibly supportive. For example, Karen Rook $(1987,1990)$ has made the compelling argument that social relationships are not only a source of explicit help with problems, but are also a source of pleasurable shared activity, which she calls companionship. She has shown in several studies that having companionate relationships leads to greater psychological well-being. Furthermore, she and others have found evidence that companionship can buffer the effects of stressors on well-being (Buunk, 1988; Rook, 1987). Our finding that only discretionary social interactions buffered the effects of examination stress is consistent with Rook's results. Presumably, many of these discretionary interactionsplaying sports, chatting with friends and neighbors-were companionate rather than problem oriented. These results, therefore, raise the possibility that interactions that have no explicit stress-buffering goals may, nonetheless, have important stressbuffering effects.

To investigate these subtle processes, social support researchers must study the concrete interpersonal interactions of people who are experiencing stressful events, rather than rely on global perceptions of supportiveness (note that perceptions of support are, at best, weak predictors of support received under stress; Dunkel-Schetter \& Bennett, 1990). Although our measure of social integration-a measure of the average number of people the subject interacted with in specific role domains-has been a useful one, it is, nonetheless, inadequate to the task. Rather, researchers should obtain self- or observer reports on specific interactions, together with reports of associated cognitions and emotions. Suitable methodologies include behavioral observations, reports of significant others, and daily diary methods. It is at the level of specific interactions that the puzzle of social relationship effects will be solved.

\section{Limitations of This Study}

The results of this study are subject to several important limitations. First, the sample size, 56 persons, is small. We have the statistical power to detect moderate effect sizes only (J. Cohen, 1988). Perhaps perceived support affects anxiety independently of personality, but with our sample size we could not detect it. Second, the results discussed above are based on a study of acute stress: Social integration and perceived support may play different roles in coping with chronic stress. More specifically, our study focused on an anticipated acute stressor, and thus, the support effects we uncovered may not generalize to unanticipated stressors such as automobile accidents. They may, however, generalize to other anticipated stressors in the achievement domain, such as job interviews, and to such stressors in the health domain, such as surgery and major dental work.

Third, we restricted this study to a particular mental health outcome, anxiety, and therefore we cannot generalize our results to other mental health outcomes, such as depression. Finally, our sample is prone to all the generalizability problems associated with using college students as subjects (Sears, 1986). Although we know of at least one other study that showed a buffering effect of social integration in a community sample (House et al., 1989), clearly, our findings need replication with nonstudent samples.

\section{Implications}

This study provides empirical justification for Coyne and DeLongis's (1986) claim that social support research has relied too heavily on perceived-support measures of relationships. As we have seen in this study, the effects of perceived support were indistinguishable from the effects of personality and prior mental health. In contrast, we found that a crude measure of typical levels of social interaction significantly buffered the effects of examination stress. Assuming this finding replicates in other samples, it suggests that future social support research should place considerably more emphasis on structural and transactional aspects of the social environment. As noted earlier, these findings imply that we should obtain information on specific interpersonal transactions in times of stress and that we should move beyond the perspective of the person who is under stress to include the perspectives of significant others (Bolger et al., 1991; Vinokur, Schul, \& Caplan, 1987).

Finally, this study illustrates the value of intensively studying a single major stressful event to understand the causal dynamics of the stress process (Kessler, Price, \& Wortman, 1985; Leventhal \& Tomarken, 1987). Although broad-based studies of life events can uncover reliable associations between stress and health, these studies are inadequate for understanding the causal complexities that underlie such associations. Daily diary designs such as the one used here, which have been mostly restricted to minor or chronic stressors (e.g., Bolger, DeLongis, Kessler, \& Schilling, 1989; DeLongis, Folkman, \& Lazarus, 1988; Eckenrode, 1984; Stone, 1987), show particular promise in understanding the dynamics of adaptation to acutely stressful events.

\section{References}

Berkman, L. S., \& Syme, S. L. (1979). Social networks, host resistance, and mortality: A nine year follow-up study of Alameda County residents. American Journal of Epidemiology, 109, 186-204.

Bolger, N. (1990). Coping as a personality process: A prospective study. Journal of Personality and Social Psychology, 59, 525-537.

Bolger, N., DeLongis, A., Kessler, R. C., \& Schilling, E. A. (1989). Effects of daily stress on negative mood. Journal of Personality and Social Psychology, 57, 808-818. 
Bolger, N., Kessler, R. C., \& Schilling, E. A. (1991). Visible support, invisible support, and adjustment to daily stress. Manuscript submitted for publication.

Bolger, N., \& Schilling, E. A. (in press). Personality and the problems of everyday life: The role of neuroticism in exposure and reactivity to daily stressors. Journal of Personality.

Buunk, B. (1988, July). Companionship and support in organizations: A microanalysis of the stress-reducing features of social interaction. Paper presented at the 4th International Conference on Personal Relationships, Vancouver, Canada.

Clark, M. S., \& Williamson, G. M. (1989). Mood and social judgments. In H. Wagner \& A. Manstead (Eds.), Handbook of social psychophysiology (pp. 347-370). Chichester, England: Wiley.

Cohen, J. (1988). Statistical power analysis for the behavioral sciences (2nd ed.). Hillsdale, NJ: Erlbaum.

Cohen, J., \& Cohen, P. (1983). Applied multiple regression/correlation analysis for the behavioral sciences (2nd ed.). Hillsdale, $\mathrm{NJ}$ : Erlbaum.

Cohen, L. H., Towbes, L. C., \& Flocco, R. (1988). Effects of induced mood on self-reported life events and perceived and received social support. Journal of Personality and Social Psychology, 55, 669-674.

Cohen, S. (1991). Social supports and physical health: Symptoms, health behaviors, and infectious diseases. In A. L. Greene, E. M. Cummings, \& K. H. Karraker (Eds.), Life-span developmental psychology: Perspectives on stress and coping (pp. 213-234). Hillsdale, NJ: Erlbaum.

Cohen, S., \& Edwards, J. R. (1989). Personality characteristics as moderators of the relationship between stress and disorder. In R. W. J. Neufeld (Ed.), Advances in the investigation of psychological stress (pp. 235-283). New York: Wiley.

Cohen, S., Sherrod, D. R., \& Clark, M. S. (1986). Social skills and the stress-protective role of social support. Journal of Personality and Social Psychology, 50, 963-973.

Cohen, S., \& Syme, S. L. (Eds.). (1985). Social support and health. San Diego, CA: Academic Press.

Cohen, S., \& Wills, T. A. (1985). Stress, social support, and the buffering hypothesis. Psychological Bulletin, 98, 310-357.

Costa, P. T., Jr., \& McCrae, R. R. (1980). Influence of extraversion and neuroticism on subjective well-being: Happy and unhappy people. Journal of Personality and Social Psychology, 38, 668-678.

Coyne, J. C., \& Bolger, N. (1990). Doing without social support as an explanatory concept. Journal of Social and Clinical Psychology, 9, 148-158.

Coyne, J. C., \& DeLongis, A. (1986). Going beyond social support: The role of social relationships in adaptation. Journal of Consulting and Clinical Psychology, 54, 454-460.

Coyne, J. C., \& Downey, G. (1991). Social factors and psychopathology: Stress, social support, and coping processes. Annual Review of Psychology, 42, 401-425.

Cutrona, C. E., \& Russell, D. (1987). The provisions of social relationships and adaptation to stress. In W. H. Jones \& D. Perlman (Eds.), Advances in personal relationships (Vol. 1, pp. 37-68). Greenwich, CT: JAI Press.

DeLongis, A., Folkman, S., \& Lazarus, R. S. (1988). The impact of daily stress on health and mood: Psychological and social resources as mediators. Journal of Personality and Social Psychology. 54, 486489.

Donald, C. A., \& Ware, J. E., Jr. (1982). The quantification of social contacts and resources. Santa Monica, CA: Rand Corporation.

Dunkel-Schetter, C., \& Bennett, T. L. (1990). Differentiating the cognitive and behavioral aspects of social support. In B. R. Sarason, I. G. Sarason, \& G. R. Pierce (Eds.), Social support: An interactional view (pp. 267-296). New York: Wiley.

Eckenrode, J. (1984). The impact of chronic and acute stressors on daily reports of mood. Journal of Personality and Social Psychology, 46, 907-918.

Eckenrode, J., \& Wethington, E. (1990). The process and outcome of mobilizing social support. In S. Duck \& R. C. Silver (Eds.), Personal relationships and social support (pp. 83-103). Newbury Park, CA: Sage.

Endler, N. S., \& Edwards, J. (1982). Stress and personality. In L. Goldberger \& S. Breznitz (Eds.), Handbook of stress: Theoretical and clinical aspects (pp. 36-48). New York: Free Press.

Eysenck, H. J., \& Eysenck, M. W. (1985). Personality and individual differences. New York: Plenum.

Eysenck, H. J., \& Eysenck, S. B. G. (1964). Manual of the Eysenck Personality Inventory. San Diego, CA: Educational and Industrial Testing Service.

Folkman, S., \& Lazarus, R. S. (1985). If it changes it must be a process: Study of emotion and coping during three stages of a college examination. Journal of Personality and Social Psychology, 48, 150-170.

Gottlieb, B. H. (1983). Social support strategies. Beverly Hills, CA: Sage.

Hammen, C., Mayol, A., deMayo, R., \& Marks, T. (1986). Initial symptom levels and the life-event depression relationship. Journal of $A b-$ normal Psychology, 95, 114-122.

Hansson, R. O., Jones, W. H., \& Carpenter, B. N. (1984). Relational competence and social support. In P. Shaver (Ed.), Review of personality and social psychology (pp. 265-284). Beverly Hills, CA: Sage.

Heller, K. (1979). The effects of social support: Prevention and treatment implications. In A. P. Goldstein \& F. H. Kanfer (Eds.), Maximizing treatment gains: Transfer enhancement in psychotherapy (pp. 353-382). San Diego, CA: Academic Press.

Henderson, S., Byrne, D. G., \& Duncan-Jones, P. (1981). Neurosis and the social environment. San Diego, CA: Academic Press.

House, J. S., \& Kahn, R. L. (1985). Measures and concepts of social support. In S. Cohen \& S. L. Syme (Eds.), Social support and health (pp. 83-108). San Diego, CA: Academic Press.

House, J. S., Robbins, C., \& Metzner, H. L. (1982). The association of social relationships and activities with mortality: Prospective evidence from the Tecumseh Community Health Study. American Journal of Epidemiology, 116, 123-140.

House, J. S., Umberson, D., \& Landis, K. (1988). Structures and processes of social support. Annual Review of Sociology, 14, 293-318.

House, J. S., Williams, D. R., \& Kessler, R. C. (1989). Social integration, social support, and the health effects of unemployment. Manuscript submitted for publication.

Kessler, R. C., \& McLeod, J. D. (1985). Social support and mental health in community samples. In S. Cohen \& S. L. Syme(Eds.), Social support and health (pp. 219-240). San Diego, CA: Academic Press.

Kessler, R. C., Price, R. H., \& Wortman, C. B. (1985). Social factors in psychopathology: Stress, social support, and coping processes. $A n$ nual Review of Psychology, 36, 351-372.

Leventhal, H., \& Tomarken, A. (1987). Stress and illness: Perspectives from health psychology. In S. V. Kasl \& C. L. Cooper (Eds.), Stress and health: Issues in research methodology (pp. 27-55). New York: Wiley.

Lieberman, M. A. (1986). Social supports-The consequences of psychologizing: A commentary. Journal of Consulting and Clinical Psychology, 54, 461-465.

Lorr, M., \& McNair, D. M. (1971). The Profile of Mood States manual. San Diego, CA: Educational and Industrial Testing Service.

Moen, P., Dempster-McClain, D., \& Williams, R. M., Jr. (1989). Social integration and longevity: An event history analysis of women's roles and resilience. American Sociological Review, 54, 635-647.

Monroe, S. M. (1983). Social support and disorder: Toward an untan- 
gling of cause and effect. American Journal of Community Psychology, 11, 81-97.

Monroe, S. M., Bromet, E. J., Connell, M. M., \& Steiner, S. C. (1986). Social support, life events, and depressive symptoms: A one-year prospective study. Journal of Consulting and Clinical Psychology, 54, 424-431.

Monroe, S. M., \& Steiner, S. C. (1986). Social support and psychopathology: Interrelations with preexisting disorder, stress, and personality. Journal of Abnormal Psychology, 95, 29-39.

Ormel, J., Stewart, R., \& Sanderman, R. (1989). Personality as a modifier of the life change-distress relationship: A longitudinal modelling approach. Social Psychiatry and Psychiatric Epidemiology, 24, 187-195.

Procidano, M. E., \& Heller, K. (1983). Measures of perceived social support from friends and from family: Three validation studies. American Journal of Community Psychology, 11, 1-24.

Rook, K. S. (1987). Social support vs. companionship: Effects on life stress, loneliness, and evaluations by others. Journal of Personality and Social Psychology, 52,1132-1147.

Rook, K. S. (1990). Social relationships as a source of companionship: Implications for older adults' psychological well-being. In B. R. Sarason, I. G. Sarason, \& G. R. Pierce (Eds.), Social support: An interactional view (pp. 219-250). New York: Wiley.

Russell, D., \& Cutrona, C. E. (1984, August). The provisions of social relationships and adaptation to stress. Paper presented at the 92nd Annual Convention of the American Psychological Association, Toronto, Canada.

Sarason, B. R., Pierce, G. R., \& Sarason, I. G. (1990). Social support: The sense of acceptance and the role of relationships. In B. R. Sarason, I. G. Sarason, \& G. R. Pierce (Eds.), Social support: An interactional view (pp. 97-128). New York: Wiley.

Sarason, B. R., Sarason, I. G., \& Pierce, G. R. (1990). Social support: An interactional view. New York: Wiley.

Sarason, I. G., \& Sarason, B. R. (1985). Social support: Insights from assessment and experimentation. In I. G. Sarason \& B. R. Sarason (Eds.), Social support: Theory, research and applications (pp. 39-50). Dordrecht, The Netherlands: Martinus-Nijhoff.

Sarason, I. G., Sarason, B. R., \& Shearin, E. N. (1986). Social support as an individual difference variable: Its stability, origins, and relational aspects. Journal of Personality and Social Psychology, 50, 845-855.
Sears, D. O. (1986). College sophomores in the laboratory: Influences of a narrow data base on social psychology's view of human nature. Journal of Personality and Social Psychology, 51, 515-530.

Spielberger, C. D., Gorsuch, R. L., \& Lushene, R. E. (1970). Manual for the State-Trait Anxiety Inventory. Palo Alto, CA: Consulting Psychologists Press.

Stone, A. A. (1987). Event content in a daily survey is differentially associated with concurrent mood. Journal of Personality and Social Psychology, 52, 56-58.

Tardy, C. H. (1985). Social support measurement. American Journal of Community Psychology, 13, 187-202.

Thoits, P. A. (1982). Conceptual, methodological, and theoretical problems in studying social support as a buffer against life stress. Journal of Health and Social Behavior, 23, 145-159.

Thoits, P. A. (1983). Multiple identities and psychological well-being: A reformulation and test of the social isolation hypothesis. American Sociological Review, 48, 174-178.

Turner, R. J. (1981). Social support as a contingency in psychological well-being. Journal of Health and Social Behavior, 22, 357-367.

Vaux, A. (1988). Social support. New York: Praeger.

Vinokur, A., Schul, Y., \& Caplan, R. (1987). Determinants of perceived social support: Interpersonal transactions, personal outlook, and transient affective states. Journal of Personality and Social Psychology, 53, 1137-1145.

Watson, D., \& Tellegen, A. (1985). Toward a consensual structure of mood. Psychological Bulletin, 98, 219-235.

Weiss, R. (1974). The provisions of social relationships. In Z. Rubin (Ed.), Doing unto others (pp. 17-26). Englewood Cliffs, NJ: PrenticeHall.

Wethington, E., \& Kessler, R. C. (1986). Perceived support, received support, and adjustment to stressful life events. Journal of Health and Social Behavior, 27, 78-89.

Williams, A., Ware, J. E., \& Donald, C. A. (1981). A model of mental health, life events, and social support applicable to general populations. Journal of Health and Social Behavior, 22, 324-336.

Received November 22, 1989

Revision received October 5, 1990

Accepted October 18, 1990 